\title{
COMENTARIOS ACERCA DE LA CONSTRUCCIÓN DE RETABLOS EN MÉXICO, 1687-1713*
}

Elisa Vargas Lugo

Este trabajo es la síntesis de una investigación más amplia, a través del análisis formal de algunos retablos y de la información derivada de una corta colección de documentos"* fechados entre 1687 y 1713 , consistente en contratos para la construcción de retablos en los que Juan Correa, pintor mulato, colaboró con las pinturas que deberían colocarse en esos muebles. Dicha documentación contiene información acerca de unos 16 retablos. Cinco de ellos se han conservado bien; los otros han desaparecido o nunca fueron construidos. Para dar apoyo a ciertas afirmaciones, he presentado como ejemplos, algunos retablos que no se mencionan en la documentación o en los cuales no trabajó Correa.

El retablo más antiguo en que colaboró Juan Correa ${ }^{1}$ es el de Santa Ana, en la Capilla del Rosario del templo de Azcapotzalco, fechado en 1681. El retablo dedicado a Jesús Nazareno de la iglesia de Thalmanalco, es de $1694^{2}$ y los tres más recientes son de la Capilla de los Ángeles de la Catedral Metropolitana, ${ }^{3}$ terminados en 1713. A través de la revisión de este material plástico y documental, he tratado de profundizar en los diferentes aspectos que determinaban la construcción de los retablos; proceso que no se ha estudiado con amplitud. Debo aclarar

* Este trabajo constituye una síntesis parcial de un artículo mayor, que forma parte del Tomo III, titulado Cuerpo de Documentos, perteneciente a la serie de cuatro tomos que constituye una investigación sobre la vida y la obra del pintor Juan Correa.

** La mayor parte de los documentos aquí citados fueron publicados por Guillermo Tovar de Teresa bajo el título Indice de Documentos relativos a Juan Correa, maestro de pin. tor; existentes en el Archivo de Notarias de la Ciudad de México, México, Ediciones El Equilibrista, 1988.

1 La firma puede verse en el lienzo que representa El Nacimiento de la Virgen.

2 Obligación de obra para la ejecución de un retablo lateral de la advocación de Jestis Nazareno, para la iglesia de San Luis Obispo de Tlalmanalco. México, 7 de julio de 1694, Archivo de Notarías de la Ciudad de México, escribano real, José de Anaya y Bonillo. fs. $91 \mathrm{r} .93 \mathrm{v}$.

3 Cfr. Efraín Castro. "Manuel de Nava, un escultor y ensamblador mexicano de los siglos xvi y xviı". Nuevo Museo Mexicano, México, 1985, núm. 1, vol. 1, pp. 53-66. 
que éste es sólo el principio de un género de investigación que deberá ser incrementado considerablemente.

\section{Los contratos}

Solemne y muy importante fue la celebración de los contratos entre patronos y artistas. Como resulta evidente en cinco de los documentos estudiados, la presentación de una traza era solicitada ex oficio, y el maestro debía someter a un notario dicha traza o montea, ${ }^{4}$ o el pitipie de sus composiciones, para asegurar así el cumplimiento exacto del diseño aprobado. Al parecer sólo ha llegado a nuestras manos un ejemplo del siglo Xvir, de ese tipo de documentos. Se trata del diseño para un sencillo retablo en piedra, para un templo de la ciudad de San Luis Potosi $^{5}$

\section{La estructura y la ornamentación}

La documentación prueba que al menos en el último cuarto del siglo XVII, la rígida estructura retablesca llamada de cuadrícula (patrón que afecta las líneas de un damero) de origen renacentista, fue modificada, dando a algunos retablos un diseño con movimiento de biombo. Uno de los casos más interesantes, ya que fue determinado por razones funcionales, fue el retablo dedicado a San Ignacio, en el templo de San Pedro y San Pablo, en donde, a causa de las limitaciones espaciales se solicitó con cinco calles, aclarando que las dos "...en los extremos de las paredes se han de resaltar para adentro por no embarazar la puerta, ni tapar por el otro lado, el retablo que está puesto, de Nuestra Señora de Guadalupe". ${ }^{6}$

4 Obligación de obra de un colateral... México, 12 de enero de 1678, Archivo de Notarías de la Ciudad de México, escribano real Baltasar Morante, fs.15r-18r.

5 Este dibujo se conserva en el Archivo Histórico de la Ciudad de San Luis Potosí.

6 Concierto de obra para... un colateral de San Ignacio..., México, 8 de marzo de 1678. Archivo de Notarías de la Ciudad de México, escribano real Marcos Pacheco de Figueroa, fs.9-10v y 15r. Cfr. Del mismo escribano el documento: Forma y condiciones para la ejecución del retablo de San Ignacio... s/f, fs.7-8v. 
El empleo de basamentos de mampostería, para retablos de madera dorada, se solicitó para el altar que se diseñó para la iglesia de Tula, ${ }^{7}$ y un ejemplo concreto de este tipo de estructuras existe en el retablo dedicado a Jesús Nazareno en la iglesia de Tlalmanalco. Debido al bajo costo de estos retablos: 550 pesos por el de Tula ${ }^{8}$ y 400 por el de Tlalmanalco, se puede deducir que los altares de mampostería eran los más baratos.

Muy importante elemento estructural de los retablos, mencionado en varios documentos, son los macizos o bases para los soportes verticales. Dichos elementos fueron usados - como claramente puede constatarse en los retablos que se han conservado- no sólo como partes estructurales sino como sobresalientes motivos ornamentales, ya que se les dio la forma de pelicanos, amorcillos semicubiertos con bandas, niños con roleos, mascarones o bichas. ${ }^{9}$ Muchos ejemplos de estos tipos de soportes o macizos lucen todavía, predominando los que tienen forma de pelícanos o de niños o angelillos atlantes.

Es interesante señalar algo que revela el creciente dinamismo del arte barroco: en la Capilla de los Ángeles de la Catedral Metropolitana, en el retablo principal los macizos se desplazaron de su posición original, perdiendo así su función tectónica, al ser colocados hacia el centro de las calles, en vez de que se respetaran los ejes verticales marcados por lo apoyos.

Es bien conocido el hecho de que los soportes preferidos en esa etapa del desarrollo del barroco, fueron las columnas salomónicas, con capiteles de linaje corintio, llamados de orden compósito. Esta preferen-

7 Conciento de obra para... un retablo... para la iglesia de Tula, México, 23 de mayo de 1692, Archivo de Notarías de la Ciudad de México, escribano real Nicolás Varela, fs.160v-162r.

8 Ibidem y además: Concierto para la ejecución de un colateral..., 13 de mayo de 1694. Archivo de Notarías de la Ciudad de México, escribano real Martín del Río, fs.373374v.

9 Cfr. Forma y condiciones para la ejecución del retablo de San Ignacio.., México, s/f, Archivo de Notarias de la Ciudad de México, escribano real Marcos Pacheco de Figueroa, fs. 7-8v., Obligación de obra para la ejecución del retablo mayor de la iglesia de Xacotitlán..., México, 6 de junio de 1678, Archivo de Notanías de la Ciudad de México, escribano real Baltasar Morante, fs.270v-277v., Concierto de obra para la ejecución de un colateral.., México, 16 de marzo de 1694, Archivo de Notarias de la Ciudad de México, escribano real Martín del Río, fs.225v. y 228, Forma y condiciones para la ejecución de un retablo..., México, 16 de marzo de 1694, Archivo de Notarias de la Ciudad de México, escribano real Martín del Río, fs.226-227v. y Concierto de obra para la ejecución de un colateral... de la Virgen de la Concepción..., México, 13 de mayo de 1694, Archivo de Notarías de la Ciudad de México, escribano real Martín del Rio, fs.373-374v. 
cia formal consta también en los documentos. ${ }^{10} \mathrm{El}$ orden corintio se pidió, por ejemplo, para las columnas del retablo de Tlalmanalco. ${ }^{11}$ Sólo en dos casos se especificó el tipo de ornamentación que deberían llevar las salomónicas; para un retablo de la ciudad de Querétaro ${ }^{12}$ se solicitó, para el primer registro, "...seis columnas del más hermoso relieve, parecidos a sus capiteles, compósitos, de muy rica talla"; y para un retablo para la ciudad de Zacatecas, en el contrato se piden salomónicas con guías vitíneas. ${ }^{13}$

Otro tipo de soporte, que aun no ha sido bien estudiado, es el que aparece alternando con columnas salomónicas en el mencionado retablo de Santa Ana. Esta modalidad muestra el fuste totalmente cubierto con bajorrelieves de variados diseños, en ritmos geométricos. Al parecer esta moda no sólo antecedió a la salomónica sino que coexistió con ella.

Un importante elemento en los retablos, es el sagrario o tabernáculo, el cual, en esa época se ve, generalmente, estructurado con salomónicas pareadas, como puede verse en el retablo de Jesús de Nazareno en Tlalmanalco. El apego a la interpretación del contrato, en este caso, se puede corroborar a través del documento. ${ }^{14}$ Por otro lado hay muchos sagrarios con columnas salomónicas pareadas, que pueban la preferencia por este modelo al final del siglo XvII.

10 Obligación de obra para la ejecución de un retablo lateral de la advocación de Jestús Nazareno, para la iglesia de San Luis Obispo de Tlalmanalco..., México, 7 de julio de 1694, Archivo de Notarías de la Ciudad de México, escribano real José de Anaya y Bonillo, fs.91r.93v.

11 Ibidem.

12 Concierto de obra para la ejecución de un colateral... de la Virgen de la Concepción.., México, 13 de mayo de 1694. Archivo de Notarías de la Ciudad de México, escribano real Martín del Rio, fs.373-374v.

13 Forma y condiciones para la ejecución de un retablo... México, 16 de marzo de 1694, Archivo de Notarías de la Ciudad de México, escribano real Martín del Río, fs.226$227 \mathrm{v}$.

14 Forma y condiciones para la ejecución de un retablo de San Ignacio..., México, s/f, Archivo de Notarías de la Ciudad de México, escribano real Marcos Pacheco de Figueroa, fs. 7-8, Concierto de obra para la ejecución de un colateral..., México, 16 de marzo de 1694, Archivo de Notarías de la Ciudad de México, escribano real Martín del Río, fs.225v. y 228, Forma y condiciones para la ejecución de un retablo..., México, 16 de marzo de 1694, Archivo de Notarías de la Ciudad de México, escribano real Martín del Río, fs.226227v., Concierto de obra para la ejecución de un colateral... de la Virgen de la Concepción...., México, 13 de mayo de 1694, Archivo de Notarías de la Ciudad de México, escribano real Martín del Río, fs.373-374v., y Obligación de obra para la ejecución de un retablo lateral de la advocación de Jesús Nazareno, para la iglesia de San Luis Obispo de Tlalmanalco..., México, 7 de julio de 1694, Archivo de Notarías de la Giudad de México, escribano real José de Anaya y Bonillo, fs $91 \mathrm{r}$-93v. 
Los grandes nichos para colocar las imágenes principales en cada retablo, se conocen como fanales, fueron empleados desde esta etapa como grandes recursos ornamentales. El del retablo de Tlalmanalco, tantas veces mencionado, conserva sus líneas sencillas, tal como se menciona en el documento; pero en otros contratos ${ }^{15}$ hay especificaciones para construir los fanales con planta octogonal, como algunos que se conservan. Este elemento que, desde luego, fue empleado con suma riqueza en el siglo XviI, había sido ya determinante en el desarrollo del barroco del siglo XVII.

Varios especialistas consideran que la moda de incorporar la luz de las ventanas al conjunto del retablo -cuando lo arquitectura del templo lo permite- fue uno de los avances sobresalientes del arte retablesco del siglo xviI. Sin embargo, como lo registran los documentos estudiados la solución de cubrir las caras interiores de las ventanas con relieves tallados, dorados, integrando así la luminosidad que llega del exterior, al esplendor del retablo, comenzó en la Nueva España, por lo menos hacia $1687,{ }^{16}$ tal como lo pide un contrato de ese año, que exige que la ventana fuera "...forrada, y guarnecida y coronada con cornisas y molduras..." y que en la parte baja hubiera un "...derrame con niños".

\section{Terminología}

Estos documentos han dado a conocer algunos términos especiales del lenguaje retablesco. Los contratos piden que las estructuras estén adornadas con: tarjas, bichas, imágenes en relieve o medio relieve, cartelas, molduras, niños, muchachos o motilos, resaltos, cortezas de todo relieve, toca-

15 Concierto de obra para la ejecución de un colateral..., México, 16 de marzo de 1694, Árchivo de Notarías de la Ciudad de México, escribano real Martín del Río, fs.225v y 228, Forma y condiciones para la ejecución de un retablo..., México, 16 de marzo de 1694, Archivo de Notarías de la Ciudad de México, escribano real Martín del Río, f's.226$227 v_{-}$, Conciento de obra para la ejecución de un colateral de la Virgen de la Concepción..., México, 13 de mayo de 1694, Archivo de Notarías de la Ciudad de México, escribano real Martín del Rio, fs.373-374v., y Obligación de obra para la ejecución de un retablo lateral de la advocación de Jesuis Nazareno, para la iglesia de San Luis Obispo de Tlalmanalco..., México, 7 de julio de 1694, Archivo de Notarías de la Ciudad de México, escribano real José de Anaya y Bonillo, fs.91r-93v.

${ }_{16}$ Forma y condiciones para la ejecución de un retablo de San Ignacio .., México, s/f, Archivo de Notarías de la Ciudad de México, escribano real Marcos Pacheco de Figueroa, fs. 7-8v., y Obligación de obra para la ejecución del retablo mayor de la iglesia de Xocotitlán, México, 7 de julio de 1678, Archivo de Notarías de la Ciudad de México, escribano real Baltasar Morante, fs $270 \mathrm{v} \cdot-277 \mathrm{v}$. 
duras, pinjantes, cogollos, bandejas, etcétera; todos estos términos se encuentran registrados ya en el Léxico de los Alarifes de los Siglos de Oro, ${ }^{17}$ a excepción de la palabras motilo y bandeja. Motilo es una palabra vasca que significa muchacho, posiblemente introducida a la Nueva España por artesanos de ese origen. Un documento establece, por ejemplo, que "...a los lados de las entrecalles dos cuerpecillos con sus lienzos y motilos, guarniciones que hacen coronación de una cornisa con sus frontis, tarjas y arbotantes" ${ }^{18}$ Como puede verse en los retablos que han llegado a nuestros días los motilos son representaciones de muchachos de diversas edades. Los hay adolescentes y los hay infantes y no se sabe a cuáles se llamaba en particular motilos; posiblemente la palabra podía usarse indistintamente, pero el caso es que dentro de este género de imágenes se cuentan niños, amorcillos, niños tenantes, angelitos y muchachos. Algunos indudablemente pueden considerarse putti.

Otra moda ornamental que apenas recientemente ha sido destacada, se menciona específicamente en algunos de estos documentos y además, aun quedan muchos bien conservados ejemplos de ella. Consiste en perfilar las formas ornamentales con una fina línea negra. Importante y bello ejemplo es el retablo de los Santos Cosme y Damián, en la Catedral Metropolitana. Específicamente, un texto señala que el retablo debería tener: "...todo el fondo del retablo" perfilado con una línea negra, para dar fuerza a la talla, con la aclaración de que la colocación de esta pintura fuera "...de suerte que no sea ahorro de oro". ${ }^{19}$ Pero todavía es necesario investigar el momento culminante de esta modalidad en México, con el objeto de establecer su lugar en el desarrollo artístico del siglo xvIr; posiblemente -como se dijo- antecedió al estilo salomónico y fue desplazada por él.

\section{Materiales}

En los documentos estudiados sólo dos clases de madera se mencionan para la hechura de los retablos. El ayacahuite y el cedro. El ayaca-

17 Fernando García Salinero, Léxico de Alarifes de los Siglos de Oro, Madrid, Real Academia Española, 1968.

18 Concierto de obra... para un retablo... para la iglesia de Tula, México, 23 de mayo de 1692, Archivo de Notarías de la Ciudad de México, escribano real Nicolás Varela, fs. $160 \mathrm{v} .162 \mathrm{r}$.

19 Forma y condiciones para la ejecución de un vetablo... México, 16 de marzo de 1694. 
huite es un árbol de la familia de las coníferas, que crece en regiones altas y frías. En español se le da el nombre de pino-real. Por otra parte el cedro mexicano pertenece a la familia de las cupresáceas y no a la de las abietáceas, como los enormes y verdaderos cedros del Líbano y de otras partes del mundo; sin embargo su madera es también de color rojizo, algo quebradiza y fue constantemente usada para la fabricación de retablos.

$\mathrm{El}$ cronista Muñoz Camargo, ${ }^{20}$ informa lo siguiente sobre el ayacahuite:

Ay otras maneras de pino muy altísimos que no llevan resina, que son a manera de pinavetes... aunque no tiene llamarada la hevra que hace el pinavete, el cual llaman los naturales Ayauhguaguitl, que es una madera blanca y muy tupida, pesada y tiesa, que es la que en esta tierra se labra para caxas y puertas, y para hacer retablos... ay muy grande muchedumbre en las sierras nevadas de Huexotsingo y Calpan.

Queda claro, por lo tanto que aun antes de 1579-1585, en que Muñoz Camargo escribió, la madera de ayacahuite ya era considerada como una de las mejores para la fabricación de retablos.

Por lo que se refiere al oro, el otro material de primerísima importancia económica y alegórica -con que se hacía el recubrimiento total de los retablos- se comprueba el hecho de que se empleaba metal del más alto quilate. En los documentos se menciona el empleo de "...oro de 23..." y de "...oro de todos los kilates..." El de ley más baja, fue de 22 quilates y se solicitó para un retablo para la ciudad de Querétaro. ${ }^{21}$

\section{Algunos maestros retableros de ese tiempo}

En los contratos se encontraron los nombres de diez maestros entalladores, escultores, ensambladores y doradores, asociados al pintor Juan Correa. Éstos son: Antonio de Roa, Felipe de Roa, Andrés de Roa, Francisco Rodriquez de Santiago, Manuel de Nava, Alonso de Xerés, Tomás Xuárez, Andrés de Fuentes y el organista Francisco Peláez. Juan Correa pintó para tres retablos diseñados por Tomás Xuárez, es-

20 Diego Muñoz Camargo, Descripción de la Ciudad y Provincia de Tlaxcala .... México, UNAM, 1981. Edición de René Acuña.

21 Concierto de obra para la ejecución de un colateral de la Virgen de la Concepción, México, 7 de julio de 1694 , op cit. 
cultor y dorador indígena; en dos retablos con Alonso de Xerés y en cuatro con Manuel de Nava. Con los demás artistas, aparentemente, sólo colaboró una vez. De todas esas obras, las que se conservan son: el retablo de Jesús Nazareno en Tlalmanalco, hecho por Xuárez-Correa y los dos en la Capilla de los Ángeles de la Catedral Metropolitana en donde se puede apreciar el magnífico oficio de Manuel Nava y las últimas creaciones de Juan Correa.

\section{El pago de los retablos}

La forma de pago a los maestros retableros es otra información que se encuentra en los documentos estudiados. La manera más común y frecuente fue desde luego pagar en efectivo, pero en varias ocasiones el pago se hacía, parte en efectivo y parte en especie, o sea que en ocasiones se les pagaba con algunas esculturas y partes de los retablos que iban a ser sustituidos y seguramente también con los retablos viejos, enteros. A la vez se asienta que algunas pinturas o esculturas de los retablos viejos, se podían usar en las nuevas creaciones, práctica que se usó hasta finales del siglo XVII. Este sistema de pago debe siempre ser recordado por los historiadores del arte novohispano, cuando se analizan las formas y elementos de los retablos, pues pueden existir combinaciones anacrónicas que hagan confuso ese tipo de estudios.

De los párrafos anteriores se pueden derivar los siguientes comentarios, a manera de conclusiones:

La manufactura de retablos requería de la colaboración de más de dos artesanos, pero no se puede precisar el número exacto de los participantes que parece haber sido variable y por que además, un solo hombre podía tener dos o hasta tres oficios.

Puede afirmarse que la presentación de la traza o montea, avalada por un notario fue requisito inevitable para la firma del contrato.

Dos muy importantes avances en el dinamismo del arte barroco florecieron en el último tercio del siglo xvir. Uno fue el empleo de la planta de biombo y el otro el aprovechamiento de la luminosidad proveniente de las ventanas, para enaltecer el brillo y los efectos sobrenaturales que pretendían conseguir los artistas retableros.

Además de la modalidad salomónica dos directrices más se emplearon en ese lapso: las columnas revestidas y los perfiles negros alrededor de las formas ornamentales. En algunos casos estas modalidades apare- 
cen combinadas, pero la moda salomónica, seguramente por su significado bíblico, fue la preferida por el público y predominó por muchos años, mientras las otras desaparecieron.

La ornamentación a base de perfiles negros, deriva de modelos manieristas.

En el uso de columnas revestidas se combina la influencia manierista con algunas formas alegóricas religiosas. Por supuesto en la modalidad salomónica predominó el simbolismo religioso.

Muy importante es el hecho indiscriminatorio de la colaboración de artistas pertenecientes a diferentes clases sociales: criollos, mulatos e indios, trabajando juntos en el mismo alto nivel artístico. 